NOTA CIENTÍFICA

\title{
DOSES DE FÓSFORO, POTÁSSIO E ESPAÇAMENTOS ENTRE LINHAS NA PRODUÇÃO DE SEMENTES E FITOMASSA DE GUANDU EM SEMEADURA TARDIA
}

\section{PHOSPHORUS AND POTASSIUM DOSES ON SEEDS AND GREEN MATTER YIELD OF PIGEONPEA IN LATE SOWING}

\author{
Danila Comelis BERTOLIN ${ }^{1 *}$ \\ Marco Eustáquio de SÁ2 \\ Salatiér BUZETT| ${ }^{3}$ \\ Adriana de Souza COLOMBO 4 \\ Letícia Lisboa OLIVEIRA ${ }^{4}$ \\ Marcelo Carvalho Minhoto TEIXEIRA FILHO ${ }^{5}$
}

\begin{abstract}
RESUMO
O presente trabalho teve por objetivo avaliar o efeito de cinco doses de fósforo e quatro doses de potássio, em dois espaçamentos entre linhas, sobre a produção de sementes e fitomassa de guandu de ciclo curto. $O$ trabalho foi desenvolvido em Selvíria, Estado do Mato Grosso do Sul, com semeadura em janeiro de 2005. Para a determinar o efeito dos tratamentos foi utilizado o delineamento inteiramente casualizado, em fatorial $2 \times 5 \times 4$, com quatro repetições, sendo os tratamentos 30 e $50 \mathrm{~cm}$ entre linhas, $0,40,80,120$ e $160 \mathrm{~kg} \mathrm{ha}^{-1}$ de $\mathrm{P}_{2} \mathrm{O}_{5}$ e $0,30,60$ e $90 \mathrm{~kg} \mathrm{ha}^{-1}$ de $\mathrm{K}_{2} \mathrm{O}$. O espaçamento de $30 \mathrm{~cm}$ entre linhas proporcionou maior produção de sementes e o espaçamento de $50 \mathrm{~cm}$ maior altura de plantas e fitomassa. As adubações com fósforo e potássio foram positivas a todas as variáveis estudadas, sendo em geral as doses em torno de $120 \mathrm{~kg} \mathrm{ha}^{-1}$ de $\mathrm{P}_{2} \mathrm{O}_{5}$ e $60 \mathrm{~kg} \mathrm{ha}^{-1}$ de $\mathrm{K}_{2} \mathrm{O}$ as doses máximas de incremento de produção.

Palavras-chave: Cajanus cajan L. Millsp., fósforo, potássio, espaçamentos, sementes, fitomassa.
\end{abstract}

\begin{abstract}
Present work had the goal to evaluate the effects of five doses of phosphorus and four of potassium in two plant inter-row spacing on seeds and biomass yield of short-cycle late sowed pigeonpea. This work was developed in Selvíria, State of Mato Grosso do Sul, with sowing in January of 2005. Experimental design was a $2 \times 5 \times 4$ factorial in completely randomized block design, with four replications. Treatments were 30 and $50 \mathrm{~cm}$ plant spacings inter-row spacing, $0,40,80$, 120 and $160 \mathrm{~kg} \mathrm{ha}^{-1}$ of $\mathrm{P}_{2} \mathrm{O}_{5}$ and $0,30,60$ and $90 \mathrm{~kg} \mathrm{ha}^{-1}$ of $\mathrm{K}_{2} \mathrm{O}$. Seed yield was greater with $30 \mathrm{~cm}$ plant spacing and biomass yield and plant height with $50 \mathrm{~cm}$ plant spacing. Phosphorus and potassium fertilizer use did have a positive effect, mainly with doses around $120 \mathrm{~kg} \mathrm{ha}^{-1}$ dose of $\mathrm{P}_{2} \mathrm{O}_{5}$ and $60 \mathrm{~kg} \mathrm{ha}^{-1}$ of $\mathrm{K}_{2} \mathrm{O}$.
\end{abstract}

Key-words: Cajanus cajan L. Millsp., phosphorus, potassium, spacings, seeds, biomass.

\footnotetext{
${ }^{1}$ Engenheira Agrônoma, mestranda do programa de Pós-graduação em Produção Vegetal da Unesp, campus de Ilha Solteira. Departamento de Fitotecnia, Tecnologia de Alimentos e Sócio-Economia, Faculdade de Engenharia, Universidade Estadual Paulista (Unesp), Campus de Ilha Solteira. Passeio Monção s/n, cx.Postal 31, 15385-000, Ilha Solteira, São Paulo, Brasil. *Autora para correspondência. e-mail: dcbertolin@aluno.feis.unesp.br

2 Engenheiro Agrônomo e Professor Doutor da Unesp, campus de Ilha Solteira. Departamento de Fitotecnia, Tecnologia de Alimentos e SócioEconomia, Faculdade de Engenharia, Universidade Estadual Paulista (Unesp), Campus de Ilha Solteira. Passeio Monção s/n, cx.Postal 31, 15385-000, Ilha Solteira, São Paulo, Brasil.

3.Engenheiro Agrônomo e Professor Doutor da Unesp, campus de Ilha Solteira. Departamento de Fitossanidade, Engenharia Rural e Solos, Faculdade de Engenharia, Unesp, Campus de Ilha Solteira. Passeio Monção s/n, cx.Postal 31, 15385-000, Ilha Solteira, São Paulo, Brasil.

${ }^{4}$ Engenheira Agrônoma, mestranda do programa de Pós-graduação em Produção Vegetal da Unesp, campus de Ilha Solteira. Departamento de Fitotecnia, Tecnologia de Alimentos e Sócio-Economia, Faculdade de Engenharia, Universidade Estadual Paulista (Unesp), Campus de Ilha Solteira. Passeio Monção s/n, cx.Postal 31, 15385-000, Ilha Solteira, São Paulo, Brasil.

${ }^{5}$ Engenheiro Agrônomo, mestrando do programa de Pós-graduação em Produção Vegetal da Unesp, campus de Ilha Solteira. Departamento de Fitossanidade, Engenharia Rural e Solos, Faculdade de Engenharia, Unesp, Campus de Ilha Solteira. Passeio Monção s/n, cx.Postal 31, 15385-000, Ilha Solteira, São Paulo, Brasil.
} 
BERTOLIN, D.C. et al. Doses de fósforo, potássio e espaçamentos...

\section{INTRODUÇÃO}

O guandu é uma planta originária das regiões tropicais da África, Ásia e algumas ilhas dos mares do Sul (WHYTE et al., 1968). O guandu temse destacado no Brasil, entre as demais leguminosas forrageiras, em função de sua notável tolerância à seca e adaptação a solos pouco férteis, apresentando grande potencial de produção de fitomassa, mesmo em períodos de estiagem (WUTKE, 1987).

Conforme SEIFFERT e THIAGO (1983), para que 0 guandu possa se desenvolver satisfatoriamente há necessidade de calcário e de fósforo já que não se tem bom crescimento em solos ácidos. Em observações de OGUNWALE e OLANIYI (1978) e também de AHLAWAT e SARAF (1981) houve um desenvolvimento vigoroso do guandu pela adição de fósforo.

Observa-se geralmente, que o guandu responde menos aos fertilizantes comparado com outras espécies das regiões semi-áridas tropicais. Esta falta aparente de problemas nutricionais pode ser o motivo da realização de poucos estudos sobre a nutrição mineral desta espécie. Pesquisas à este respeito foram feitas com as cultivares tradicionais, de ciclo longo, cujo cultivo ocorre normalmente intercalar a outras culturas. Entretanto, novas cultivares de ciclo curto, permitem normalmente uma única colheita com elevado nível de produção de acordo com o manejo e por isso necessitam de estudos mais detalhados quanto às exigências nutricionais (JOHANSEN, 1990).

Segundo WUTKE et al. (1998) o espaçamento entrelinhas deve variar de 50 a 100 $\mathrm{cm}$ dependendo da época de semeadura, com espaçamentos mais amplos no período tradicional, e mais estreitos em semeaduras tardias. PEDROSO et al. (1988) evidenciaram maior produção de sementes no menor espaçamento por eles experimentado, $40 \mathrm{~cm}$, em relação aos demais espaçamentos testados de 60, 80 e $100 \mathrm{~cm}$, na densidade de 2 plantas $\mathrm{m}^{-1}$.

Visando produtividade são necessários estudos de espaçamentos reduzidos de plantio. Além disso são escassos na literatura dados a respeito de adubação de cultivares de ciclo curto de guandu. Sendo este material de baixo porte, menos lenhoso e com boa capacidade de produção de fitomassa, sua utilização é desejável em áreas de plantio direto, como adubo verde ou planta de cobertura de solo.

Objetivou-se verificar os efeitos de doses de fósforo e de potássio e espaçamento entre linhas na produção de sementes e de fitomassa de guandu (Cajanus cajan L. Millsp.) de ciclo curto.

\section{MATERIAL E MÉTODOS}

$O$ experimento de campo foi realizado na Fazenda Experimental de Ensino e Pesquisa (FEP), localizada no município de Selvíria-MS, coordenadas geográficas de $20^{\circ} 22^{\prime} \mathrm{S}$ e $51^{\circ} 22^{\prime} \mathrm{W}$, e altitude média de $335 \mathrm{~m}$. O clima da região é do tipo Aw, segundo a classificação de Köeppen e, de acordo com informações de HERNANDEZ et al. (1995), a temperatura e a precipitação média anual são de aproximadamente $23,5{ }^{\circ} \mathrm{C}$ e $1370 \mathrm{~mm}$, respectivamente, com período mais seco de abril a outubro. O solo da área experimental é do tipo Latossolo Vermelho Distrófico típico argiloso, A moderado, hipodistrófico, álico, caulinítico, férrico, compactado, muito profundo, moderadamente ácido (EMBRAPA, 1999), cuja análise química apresentou os seguintes resultados: $\mathrm{pH} \mathrm{CaCl}_{2}$ de 5,1 ; matéria orgânica $=22 \mathrm{~g} \mathrm{dm}^{-3} ; \mathrm{P}$ (resina) $=7 \mathrm{mg} \mathrm{dm}^{-3} ; \mathrm{K}=14$ mmol dm ${ }^{-3} ; \mathrm{Ca}=34 \mathrm{mmol}_{\mathrm{c}} \mathrm{dm}^{-3} ; \mathrm{Mg}=1,4 \mathrm{mmol}_{\mathrm{c}}$ $\mathrm{dm}^{-3} ; \mathrm{H}+\mathrm{Al}=28 \mathrm{mmol} \cdot \mathrm{dm}^{-3} \mathrm{e} \mathrm{V}=64 \%$.

O solo foi preparado convencionalmente, com uma aração e duas gradagens. A semeadura foi realizada manualmente em 18 de janeiro de 2005, com 20 sementes por metro de sulco, conforme as recomendações de WUTKE el al. (1993). Foram utilizadas sementes fiscalizadas de guandu cultivar IAPAR 43-Aratã.

Os tratamentos foram constituídos de dois espaçamentos entre linhas $(30$ e $50 \mathrm{~cm})$; cinco doses de fósforo $\left(0,40,80,120\right.$ e $\left.160 \mathrm{~kg} \mathrm{P}_{2} \mathrm{O}_{5} \mathrm{ha}^{-1}\right)$; e quatro doses de potássio $(0,30,60$ e $90 \mathrm{~kg} \mathrm{~K} 2 \mathrm{O}$ $\left.\mathrm{ha}^{-1}\right)$. Como fonte de nutrientes foram utilizados 0 superfosfato triplo $\left(\mathrm{P}_{2} \mathrm{O}_{5}\right)$ e cloreto de potássio $\left(\mathrm{K}_{2} \mathrm{O}\right)$. Foi utilizado o delineamento em blocos casualizados com quatro repetições em fatorial $2 \times 5 \times 4$, totalizando 40 tratamentos, e parcelas de 5 linhas de $6 \mathrm{~m}$ de comprimento.

Foram estudadas as variáveis estande inicial e final, altura de plantas, produção de fitomassa, número de vagens por planta, número de sementes por vagem e produtividade de sementes.

A colheita do experimento foi realizada manualmente. Para determinação da produção de sementes foram cortadas as plantas da linha central de cada parcela, rente ao solo, sendo o material identificado e amarrado em feixes, sendo posteriormente levado para terreiro de alvenaria até completa secagem. O material foi submetido à trilha mecânica em trilhadeira estacionária, a limpeza foi realizada manualmente, com uso de peneiras e separação manual das sementes e impurezas. Após a limpeza, os materiais foram pesados, em balança com precisão $0,1 \mathrm{~g}$ e os dados obtidos foram transformados em $\mathrm{kg} \mathrm{ha}^{-1}$.

Para determinação das demais variáveis foram coletadas 10 plantas, em $1 \mathrm{~m}$ da segunda linha de cada parcela. Para quantificar fitomassa 0 material foi pesado imediatamente após a colheita, para determinação de altura, as plantas foram medidas desde a base até o ápice do caule, utilizando-se fita métrica graduada em centímetros. O número de vagens por planta foi determinado após retirada das vagens das 10 plantas. As vagens foram debulhadas, sendo contadas as sementes e determinado o número de sementes por vagem.

Utilizou-se o programa SANEST (ZONTA e MACHADO, 1991) para realização das análises estatísticas, e os dados originais de contagens foram previamente transformados por $\mathrm{x}^{1 / 2}+0,5$ (BANZATTO 
e KRONKA, 2006). Para comparação das médias dos efeitos de espaçamentos foi realizado o teste de Tukey e para o efeito de doses foram realizadas análises de regressão polinomial conforme BANZATTO e KRONKA (2006).

\section{RESULTADOS E DISCUSSÃO}

As plantas emergiram 6 dias após a semeadura e o ciclo da cultura foi de 150 dias. O experimento foi mantido livre da concorrência de plantas daninhas por meio de capinas manuais, e de pragas pela aplicação de inseticida organofosforado.
$\mathrm{Na}$ Tabela 1 podem ser observados os quadrados médios e valores médios obtidos para estande final, altura de plantas, produção de fitomassa, número de vagens por planta, número de sementes por vagem e produtividade de sementes.

Na Tabela 2 são apresentados os valores médios, teste de Tukey para a variável espaçamentos, podendo ser observadas as equações de regressão para as variáveis estande final, altura de plantas e sementes por vagem em relação as doses de fósforo e doses de potássio.

TABELA 1 - Quadrados médios, valores médios, coeficientes de variação e teste F referentes ao estande final, altura de plantas, fitomassa, número de vagens por planta, número de sementes por vagem e produção de sementes de guandu. Selvíria, MS, 2005.

\begin{tabular}{lcccccc}
\hline & $\begin{array}{c}\text { Estande } \\
\text { final }\end{array}$ & Altura & Fitomassa & $\begin{array}{c}\text { Vagens por } \\
\text { planta }\end{array}$ & $\begin{array}{c}\text { Sementes } \\
\text { por vagem }\end{array}$ & $\begin{array}{c}\text { Produtividade de } \\
\text { sementes }\end{array}$ \\
\hline Espaçamento (E) & 0,03 & 0,22 & $52631,06^{*}$ & $446,08^{* *}$ & $4,46^{* *}$ & $5007,26^{* *}$ \\
Fósforo (P) & $4,81^{* *}$ & 0,01 & $164370,15^{*}$ & $243,16^{* *}$ & $2,00^{* *}$ & $16660,45^{* *}$ \\
Potássio (K) & 14,40 & 0,01 & $79067,77^{* *}$ & $86,14^{* *}$ & $1,58^{* *}$ & $3780,40^{* *}$ \\
Blocos & 2,40 & $0,02^{*}$ & 58879,76 & $0,11^{* *}$ & $0,01^{* *}$ & $5,43^{*}$ \\
$\mathrm{E}^{*} \mathrm{P}$ & 0,05 & $0,03^{*}$ & 503,90 & $168,18^{* *}$ & $2,55^{* *}$ & $2469,24^{* *}$ \\
$\mathrm{E}^{*} \mathrm{~K}$ & 0,06 & $0,01^{*}$ & 149,45 & $192,69^{* *}$ & $1,14^{* *}$ & $6058,88^{* *}$ \\
$\mathrm{P}^{*} \mathrm{~K}$ & 0,95 & $0,02^{*}$ & $102749,57^{* *}$ & $122,51^{* *}$ & $1,71^{* *}$ & $6758,94^{* *}$ \\
E*P$^{*} \mathrm{~K}$ & 0,06 & $0,03^{*}$ & 1016,51 & $97,73^{* *}$ & $1,80^{* *}$ & $1586,69^{* *}$ \\
Resíduo & 2,07 & 0,01 & 12895,12 & 11,52 & 0,16 & 820,31 \\
\hline Média & 14,19 & 1,58 & 451,76 & 16,40 & 2,91 & 86,97 \\
\hline CV (\%) & 10,1 & 4,9 & 25,1 & 20,7 & 13,9 & 32,9 \\
\hline
\end{tabular}

Significativo pelo teste $\mathrm{F}$ ao nível de $5 \%$ de probabilidade.

"Significativo pelo teste $\mathrm{F}$ ao nível de $1 \%$ de probabilidade.

TABELA 2 - Valores médios obtidos, teste de Tukey e regressões referentes ao estande final, altura de plantas e número de sementes por vagem de guandu. Selvíria, MS, 2005.

\begin{tabular}{|c|c|c|c|c|}
\hline & & $\begin{array}{c}\text { Estande final } \\
\text { (plantas por ha) }\end{array}$ & $\begin{array}{c}\text { Altura } \\
(\mathrm{m})\end{array}$ & Sementes por vagem \\
\hline \multirow{2}{*}{$\begin{array}{l}\text { Espaçamento entre linhas } \\
(\mathrm{cm})\end{array}$} & 30 & $473.667 \mathrm{~A}$ & $1,58 \mathrm{~A}$ & $2,11 \mathrm{~A}$ \\
\hline & 50 & $283.620 \mathrm{~B}$ & $1,61 \mathrm{~A}$ & $1,62 \mathrm{~B}$ \\
\hline \multirow{5}{*}{ Fósforo (kg ha $\left.{ }^{-1}\right)$} & 0 & $367.488^{(1)}$ & 1,55 & $2,72^{(4)}$ \\
\hline & 40 & 373.066 & 1,55 & 2,81 \\
\hline & 80 & 378.643 & 1,55 & 2,89 \\
\hline & 120 & 384.220 & 1,55 & 2,98 \\
\hline & 160 & 389.798 & 1,56 & 3,07 \\
\hline \multirow{4}{*}{ Potássio $\left(\mathrm{kg} \mathrm{ha}^{-1}\right)$} & 0 & $397.311^{(2)}$ & $1,54^{(3)}$ & $2,67^{(5)}$ \\
\hline & 30 & 384.866 & 1,55 & 2,82 \\
\hline & 60 & 372.419 & 1,56 & 2,97 \\
\hline & 90 & 359.972 & 1,57 & 3,12 \\
\hline \multicolumn{2}{|l|}{ DMS (5\%) } & 0,44 & 0,02 & 0,12 \\
\hline \multicolumn{2}{|c|}{$\mathrm{CV}(\%)$} & 9,92 & 4,15 & 14,10 \\
\hline \multicolumn{5}{|c|}{$\begin{array}{l}\text { (1) } y=367488,331641+139,4375146 \times\left(R^{2}=0,70\right) \\
\text { (2) } y=397314,331562-414,911 \times\left(R^{2}=0,99\right) \\
\text { (3) } y=1,536+0,0003667 X\left(R^{2}=0,59\right) \\
\text { (4) } y=2,725+0,0021791 X\left(R^{2}=0,40\right) \\
\text { (5) } y=2,67+0,0050798 X\left(R^{2}=0,96\right)\end{array}$} \\
\hline
\end{tabular}


BERTOLIN, D.C. et al. Doses de fósforo, potássio e espaçamentos...

Observou-se efeito positivo do fósforo para o estande final, cujos dados puderam ser ajustados a uma função linear positiva. SEIFFERT e THIAGO (1983) ressaltaram que para o guandu ter um desenvolvimento satisfatório há necessidade de calcário e fósforo, já que o crescimento é prejudicado em solos ácidos.

Houve redução do estande com o adubo potássico. TANDON (1989) afirmou que as sementes de guandu são propensas à efeito de salinidade do cloro $(\mathrm{Cl})$, quando da utilização do cloreto de potássio como fonte de $\mathrm{K}$, dada a proximidade de colocação deste adubo em relação às sementes. Embora tenha sido pequena a redução no estande com aumento da dose aplicada do adubo potássico, $9,4 \%$ na dose máxima, o fato pode ser um alerta de que as sementes desta espécie são mais sensíveis à ação salina desse adubo.

Para altura de plantas, o espaçamento de
$50 \mathrm{~cm}$ proporcionou tendência de plantas maiores em relação ao espaçamento de $30 \mathrm{~cm}$, provavelmente pela menor competição entre plantas por água, luz e nutrientes, porém o resultado não foi significativo estatísticamente. As doses crescentes de adubo potássico proporcionaram maior altura às plantas. Os resultados obtidos para produção de fitomassa acompanharam os resultados para altura. O valor médio de fitomassa produzida no espaçamento de $50 \mathrm{~cm}$ foi de $55.200 \mathrm{~kg} \mathrm{ha}^{-1}$ superando os valores obtidos por SUZUKI e ALVES (2006), que foram de $32.708 \mathrm{~kg} \mathrm{ha}^{-1}$ de fitomassa, também em guandu anão neste mesmo espaçamento, porém, sem utilização de adubação e com semeadura em setembro. Foi observada interação entre doses de fósforo e doses de potássio (Figura 1), sendo os maiores valores resultantes da combinação das doses de $60 \mathrm{~kg}$ ha $^{-1}$ de $\mathrm{K}_{2} \mathrm{O}$ com 40, 80 e $120 \mathrm{~kg} \mathrm{ha}^{-1}$ de $\mathrm{P}_{2} \mathrm{O}_{5}$.

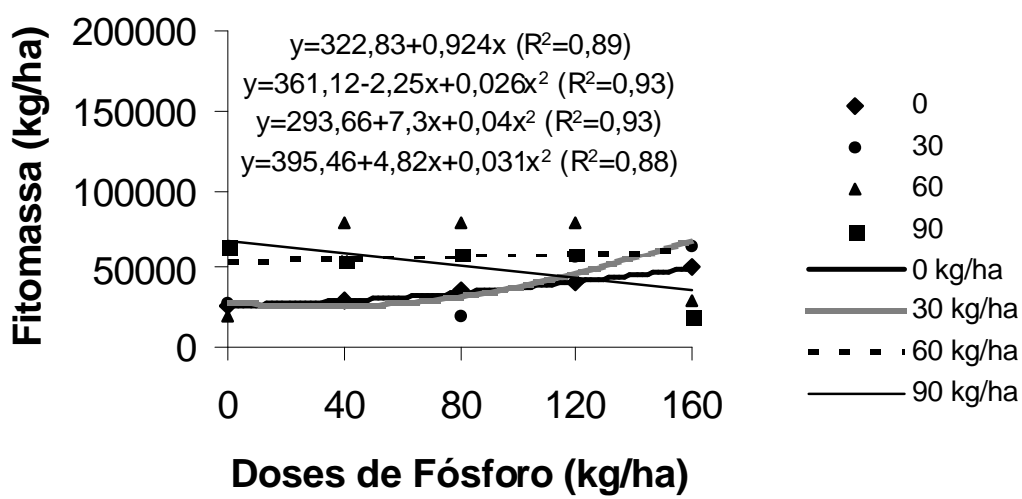

FIGURA 1 - Produção de fitomassa em guandu em função de interação entre doses de potássio e fósforo. Selvíria-MS, 2005.

A adubação com fósforo e potássio proporcionou incremento no número de vagens por planta, sementes por vagem e produção de sementes, e o espaçamento de $30 \mathrm{~cm}$ foi mais favorável em relação ao espaçamento de $50 \mathrm{~cm}$. MANJHI et al. (1973) utilizando dois espaçamentos entre linhas, 50 e $75 \mathrm{~cm}$, e três cultivares de guandu também obtiveram maior número de vagens por planta, sementes por vagem e massa de mil sementes no menor espaçamento. Neste trabalho além da utilização do espaçamento de $50 \mathrm{~cm}$ foi testado um espaçamento menor e os resultados foram positivos à tendência de se obter maior produtividade utilizando espaçamento reduzido, ou seja, com maior número de plantas por área.

Foi observada interação entre doses de fósforo e potássio para número de vagens por planta sendo os maiores valores resultantes da combinação entre as doses de 60 e $90 \mathrm{~kg} \mathrm{ha}^{-1}$ de $\mathrm{K}_{2} \mathrm{O}$ e $80 \mathrm{~kg}$ ha-1 de $\mathrm{P}_{2} \mathrm{O}_{5}$. Também para a variável vagens por planta houve interação significativa entre doses de potássio e espaçamentos, sendo as doses máximas positivas resultantes da combinação entre a dose de $45 \mathrm{~kg} \mathrm{ha}^{-1}$ de $\mathrm{K}_{2} \mathrm{O}$ e 0 espaçamento de $30 \mathrm{~cm}$ (Figura 2).
A produção de sementes foi de $3,6 \mathrm{t} \mathrm{ha}^{-1}$ no espaçamento de $30 \mathrm{~cm}$, valor superior ao obtido por SINGH et al. (1994) em experimento na Índia, também com cultivares de ciclo curto e semeadura de verão, que foi de $2,12 \mathrm{t} \mathrm{ha}^{-1}$, sendo que estes autores obtiveram esta produção de sementes no espaçamento intermediário, $75 \mathrm{~cm}$, com valores inferiores de produção em 50 a $100 \mathrm{~cm}$. Para esta variável houve interação entre doses de fósforo e potássio sendo os maiores resultados oriundos da combinação entre as doses de $160 \mathrm{~kg} \mathrm{ha}^{-1}$ de fósforo e $30 \mathrm{~kg} \mathrm{ha}^{-1}$ de potássio. Também foi observada interação para produção de sementes entre doses de potássio e espaçamentos entre linhas, sendo que a combinação mais favorável foi entre a dose de $30 \mathrm{~kg} \mathrm{ha}^{-1}$ de potássio e o espaçamento de 30 $\mathrm{cm}$ (Figura 3). LANA et al. (2001), não obtiveram resultados significativos da adubação com fósforo e potássio na produtividade de grãos de soja em condições de semeadura direta. Também SGUARIO JÚNIOR et al. (2006), não observaram significância estatística para rendimento de grãos nem para população de plantas de feijoeiro em relação à doses de potássio. 

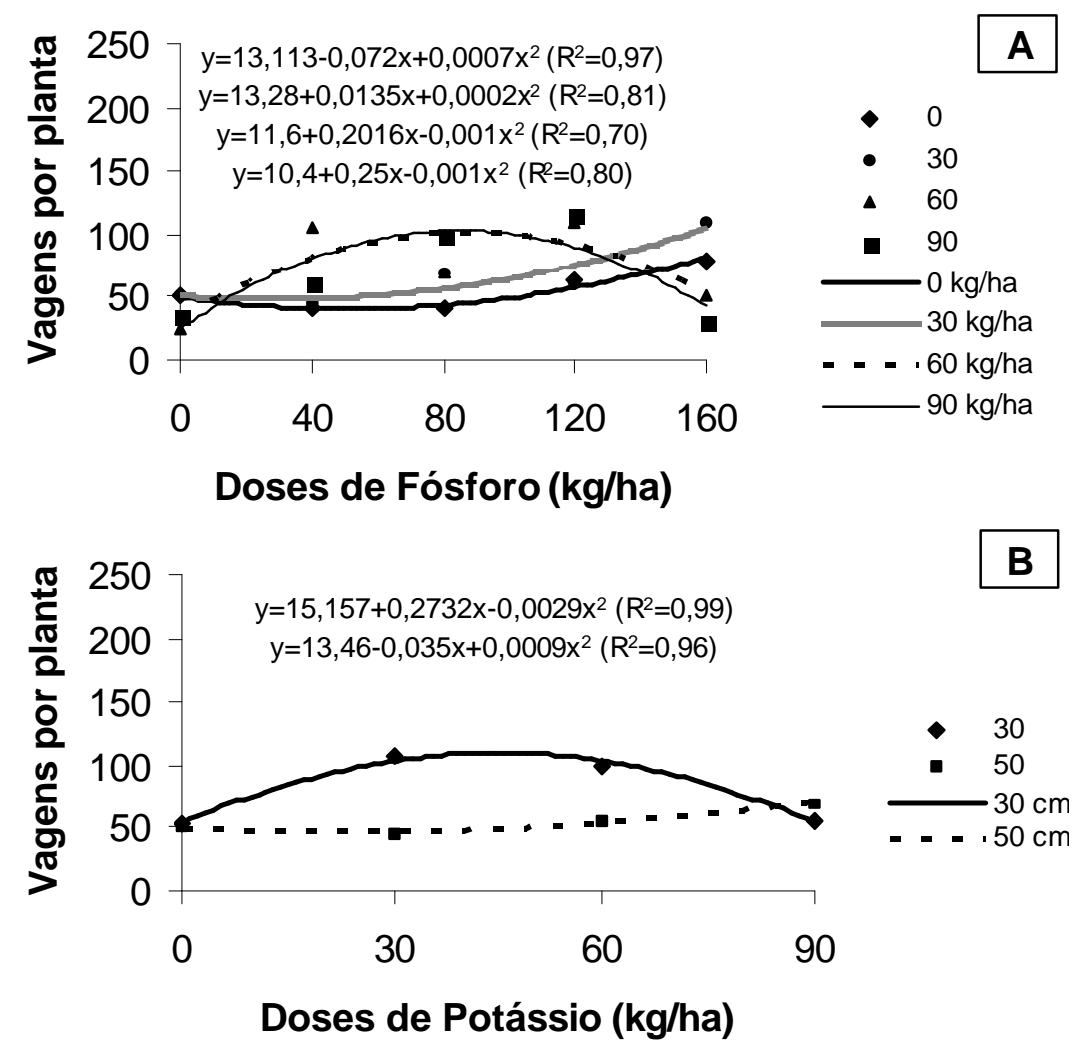

FIGURA 2 - Número de vagens por planta em guandu em função de interação entre doses de fósforo e potássio (A), e em função de doses de potássio e espaçamentos entre linhas (B). Selvíria-MS, 2005.

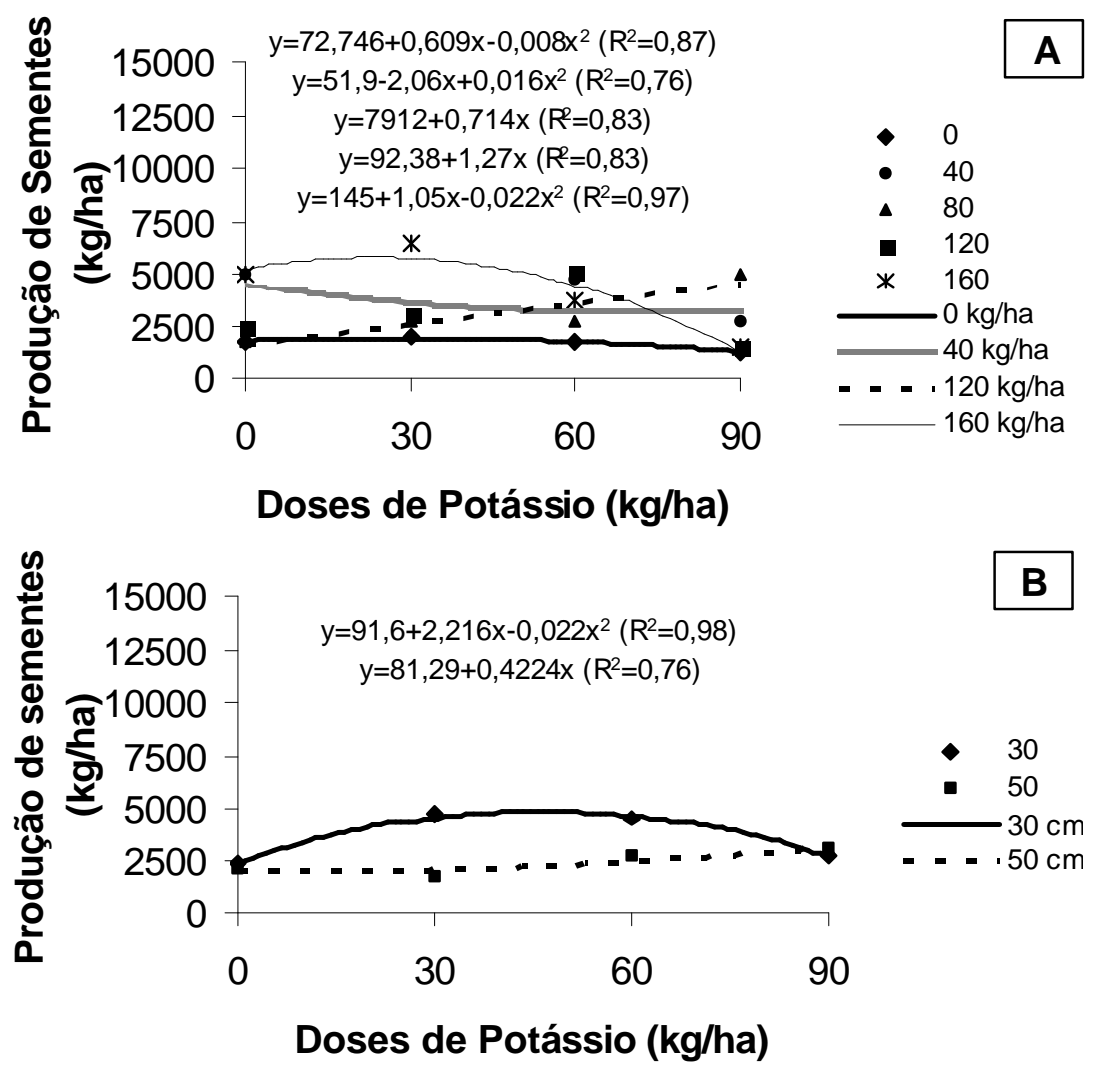

FIGURA 3 - Produção de sementes em guandu em função de interação entre doses de potássio e fósforo(A), e em função de doses de potássio e espaçamentos entre linhas (B). Selvíria-MS, 2005. 
BERTOLIN, D.C. et al. Doses de fósforo, potássio e espaçamentos...

As produtividades de sementes obtidas foram superiores àquelas mencionadas por CALEGARI et al. (1993) que são entre 1000 e 2000 $\mathrm{kg} \mathrm{ha}^{-1}$. De acordo com RAIJ (1987), na maior parte dos solos brasileiros ocorre deficiência em fósforo e, portanto, obtêm-se resposta à adubação fosfatada. Os efeitos das adubações fosfatadas nas culturas são especialmente acentuados em solos de baixa fertilidade natural.

\section{CONCLUSÕES}

1) Espaçamento menor entre linhas proporciona maior produção de sementes.

2) Espaçamento maior entre linhas proporciona maior produção de fitomassa e maior altura de plantas.
3) Adubações com fósforo e potássio incrementam os parâmetros altura, número de vagens por planta, número de sementes por vagem, produtividade de sementes e produção de fitomassa.

4) A adubação potássica via sementes sobretudo na dose de $90 \mathrm{~kg} \mathrm{ha}^{-1}$ reduz o estande de plantas.

5) A combinação entre a dose de $160 \mathrm{~kg}$ ha-1 de fósforo e a dose de $30 \mathrm{~kg} \mathrm{ha}^{-1}$ de potássio proporciona maior produtividade de sementes.

\section{AGRADECIMENTO}

Aos funcionários da Fazenda de Ensino e Pesquisa da Unesp, campus de Ilha Solteira que tornaram possível a realização deste trabalho.

\section{REFERÊNCIAS}

1. AHLAWAT, I.P.S.; SARAF, C.S. Response of pigeon pea (Cajanus cajan L. Millsp.) to plant density and phosphorus fertilizer under dryland conditions. Journal of Agricultural Science, v. 97, p. 119-124, 1981.

2. BANZATTO, D.A.; KRONKA, S. do N. Experimentação agrícola. 4. ed.Jaboticabal: FUNEP, 2006. 237 p.

3. CALEGARI, A.; ALCÂNTARA, P.B.; MIYASAKA, S.; AMADO, T.J.C. Caracterização das principais espécies. In: COSTA, M.B.B.; CALEGARI, A.; MONDARDO, A.; BULISANI, E.A.; WILDNER, L.P.; ALCÂNTARA, P.B.; MIYASAKA, S.; AMADO, T.J.C. Adubação verde no Sul do Brasil. 2. ed. Rio de Janeiro: AS-PTA, 1993. p. 207-346.

4. EMBRAPA. Empresa Brasileira de Pesquisa Agropecuária. Centro Nacional de Pesquisa de Solos. Sistema Brasileiro de Classificação de Solos. Rio de Janeiro: EMBRAPA/CNPS, 1999. 412 p.

5. HERNANDEZ, F.B.T.; LEMOS FILHO, M.A.F.; BUZZETTI, S. Software Hidrisa e o balanço hídrico de Ilha Solteira. Ilha Solteira: UNESP/FEIS/Área de Hidráulica e Irrigação, 1995. 45 p.

6. JOHANSEN, C. Pigeonpea: mineral nutrition. In: NENE, Y.L.; HALL, S.D.; SHEILA, V.K. The pigeonpea. New Delhi: CAB International, International Crops Research Institute for the Semi-Arid Tropics, 1990. p. 209-231.

7. LANA, R.M.; VILELA FILHO, C.E.; ZANÃO JÚNIOR, L.A.; PEREIRA, H.S.; LANA, A.M.Q. Adubação superficial com fósforo e potássio para a soja em diferentes épocas em pré-semeadura na instalação do sistema de plantio direto. Scientia Agraria, v. 4, n. 1-2, p. 53-60, 2003.

8. MANJHI, S.; CHOWDHURY, S.L.; KAVITKAR, A.G. Influence of varieties, planting rates, row spacings and fertilizer nutrients on the yield components of pigeonpea (Cajanus cajan (L.) Millsp.). Indian Journal of Agricultural Science, v. 43, p. 998-1001, 1973.

9. OGUNWALE, J.A.; OLANIYI, J.K. Response of pigeon pea (Cajanus cajan L. Millsp.) to phosphorus on a phosphorus marginal soil in Nigeria. East African Agricultural Forestry Journal, v. 43, p. 274-280, 1978.

10. PEDROSO, P.A.; VIEIRA, R.D; SADER, R.; SCOTTON, L.A. Efeito de espaçamentos e densidades de plantas na produção e qualidade de sementes de guandu. Revista Brasileira de Sementes, v. 10, n. 2, p. 45-53, 1988.

11. RAIJ, B. van: Fósforo: dinâmica e disponibilidade no solo. In: FERNANDES, F.M., NASCIMENTO, V.M. (Coords.). 1ㅇ $^{\circ}$ Curso de Atualização em Fertilidade do Solo. Campinas: Fundação Cargill, 1987. p. 161-179.

12. SEIFFERT, N.F.; THIAGO, L.R.L.S. Legumineira: cultura forrageira para produção de proteína. Campo Grande: EMBRAPA. CNPGC, 1983. 52 p. (Circular Técnica, 13).

13. SGUARIO JÚNIOR, J.C.; DAROS, E.; PAULETTI, V.; RONZELLI JÚNIOR, P. KOEHLER, S.H.; OLIVEIRA, R.A de. Doses e formas de aplicação de potássio na cultura do feijoeiro em sistema de plantio direto na palha. Scientia Agraria, v. 7, n. 1-2, p. 9-14, 2006.

14. SINGH, A.; AHLAWAT, I.P.S.; SHARMA, R. K. Effect of plant type, row spacing and plant population density on growth and yield of pigeonpea (Cajanus cajan) grown during summer season. Indian Journal of Agronomy, v. 39, p. 573$577,1994$.

15. SUZUKI, L.E.A.S; ALVES, M.C. Fitomassa de plantas de cobertura em diferentes sucessões de culturas e sistemas de cultivo. Bragantia, v. 65 , n. 1, p. 121-127, 2006

16. TANDON, H.L.S. Secondary and micronutrient recommendations for soils and crops: a guide book. New Delhi: Fertilizer Development and Consultation Organization, 1989. $104 \mathrm{p}$.

17. WHYTE, R.O.; NILSSON-LEISSNER, O.; TRUMBLE, H.C. Las leguminosas en la agricultura. Yugoslavian: FAO, 1968. 405 p.

18. WUTKE, E.B. Adubação verde: manejo da fitomassa e espécies utilizadas no estado de São Paulo. In: WUTKE, E.B.; BULISANE, E.A.; MASCARENHAS, H.A.A. (Coords.). $1^{\circ}$ Curso sobre adubação verde no Instituto Agronômico. Campinas: Instituto Agronômico, 1993. p.17-29. (IAC. Documentos, 35).

19. WUTKE, E.B. Caracterização fenológica e avaliação agronômica de genótipos de guandu Cajanus cajan (L.) Millsp. Piracicaba, 1987. 164 f. Dissertação (Mestrado) - Escola Superior de Agricultura Luiz de Queiroz, Universidade de São Paulo 
BERTOLIN, D.C. et al. Doses de fósforo, potássio e espaçamentos...

20. WUTKE, E.B.; MIRANDA, M.A.C.; AMBROSANO, E.J.; BRAGA, N.R.; BULISNI, E. A. Guandu - Cajanus cajan L. Millsp. In: FAHL, J.I.; CAMARGO, M.B.P, PIZZINATTO, M.A.; BETTI, J.A.; MELO, A.M.T., DE MARIA, I.C.; FURLANI, A.M.C. (Eds). Instruções agrícolas para as principais culturas econômicas. 6. ed. Campinas: Instituto Agronômico, 1998. p. 288-289. (IAC. Boletim Técnico, 200).

21. ZONTA, E.P.; MACHADO, A.A. SANEST - Sistema de análise de variância por microcomputadores. Pelotas: UFPel, 1991. $104 \mathrm{p}$

Recebido em 19/03/2007

Aceito em 18/02/2008 
